\section{Ronald Wainstein Gewölb 1961-2018}

Tempranamente, a sus 56 años, nos dejó Ronald Wainstein, médico nefrólogo y Presidente en ejercicio de la Sociedad Chilena de Nefrología. Tuvo gran entereza y valentía para sobrellevar durante más de 2 años la enfermedad que le provocó la muerte.

Ronald nació en Santiago, el 10 de Mayo, 1961, en el seno de una familia de religión judía, compuesta por su padre Eduardo, su madre Nancy y sus hermanos Claudio y Carolina. Durante su infancia y adolescencia desarrolló el gusto por la caza y la pesca, aficiones motivadas por su padre, con quien salían al campo a las 5 de la mañana los días sábados. Recibió su educación primaria y secundaria en el Liceo Experimental Manuel de Salas, un establecimiento educacional prestigioso, ligado a la Universidad de Chile. Según recuerda uno de sus mejores amigos, Daniel Alvo, Ronald era un niño tranquilo y algo retraído; le gustaba el arte (su madre es artista visual), y la biología. De esta última asignatura era profesora Graciela Ferrada, su maestra más querida. Era buen deportista, prefiriendo el esquí y la esgrima. Tuvo grandes facilidades para practicar esquí en La Parva, donde tenía un departamento su familia. Era tal su gusto por el deporte blanco, que con su amigo Daniel jugaban ajedrez en clase, para hacerse expulsar por varios días, y así poder arrancarse a la nieve.

Ronald recibió su título de médico cirujano de la Universidad de Chile en 1985, siguiendo una fuerte tradición familiar: su padre y abuelo eran médicos, y sus dos hermanos también lo son. Su abuelo Abraham, cirujano y gran anatomista, fue su profesor en la Escuela de Medicina, y tuvo gran influencia en desarrollar su vocación.

A diferencia de su padre Eduardo, quien fue por largos años cirujano digestivo-oncológico y Jefe del Departamento de Cirugía del Hospital Militar, Ronald siguió el camino de la Medicina Interna, realizando una beca de la especialidad en el Hospital San Juan de Dios. Ya como internista, ingresa al Hospital Militar en 1988, trabajando primeramente en la Unidad de Cuidados Intensivos y Coronarios, lugar donde cultivó un gusto y afinidad crecientes por la nefrología, en particular lo que representaba el cuidado de los pacientes con falla renal aguda de estas unidades. Esto hizo que gradualmente se integrara al equipo de nefrólogos

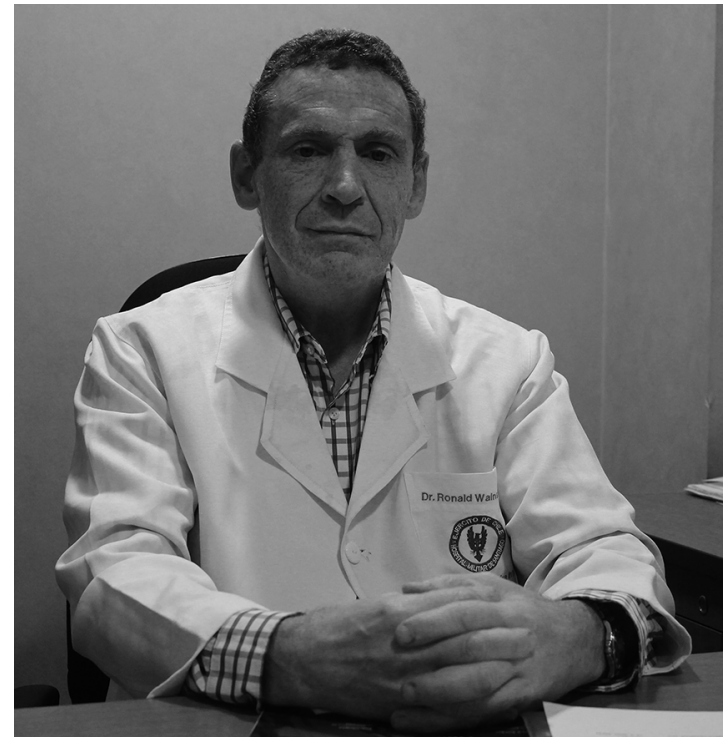

del Hospital, que en esa época, década de los 80 y 90 del siglo pasado, estaban incentivados por el desarrollo de la especialidad en todas sus áreas. Ronald hizo un gran aporte en este crecimiento de la nefrología en el Hospital, contribuyendo a implementar todas las técnicas en el tratamiento de los pacientes con insuficiencia renal aguda. Él era poseedor de una gran inteligencia para el autoaprendizaje: como ejemplo, aprendió a colocar catéteres de diálisis tunelizados, una técnica aún no aplicada en Chile en esa época, mirando un video.

En la década del 90 Ronald empezó a mirar y relacionarse con otros equipos nefrológicos en Chile, participando en la Sociedad Chilena de $\mathrm{Ne}$ frología desde 1992. En esta Sociedad formó inicialmente parte y luego llegó a presidir, el Comité de Insuficiencia Renal Aguda, y como tal lideró la contribución de esta especialidad en el protocolo de atención ministerial de las personas afectadas por terremotos y catástrofes naturales en nuestro país. En 1994 hizo una pasantía en la Unidad de Nefrología de la Clínica Mayo, USA. Desde esta época son sus pertenencias y participaciones en las Sociedades de Nefrología de otras latitudes: Sociedad Americana de Nefrología (ASN), Sociedad Latinoamericana de Nefrología e Hipertensión (SLANH, miembro de su Comité IRA) y Sociedad Internacional de Nefrología (ISN); asistiendo al 
Congreso de esta última Sociedad en Jerusalén, en 1993, tuvo la oportunidad de visitar a miembros de su familia materna (tíos y primos), que residían en Nazareth. Visitando estos lugares Ronald buscaba establecer relaciones profundas con la tierra de origen de sus ancestros, experiencia que ya había vivido en su época universitaria, al pasar un verano viviendo en un kibutz.

Durante su carrera en el Hospital Militar, y por sus cualidades personales de liderazgo, Ronald asumió la jefatura del Servicio de Medicina en el año 2006, liderando una profunda transformación, que lo cambió, de ser un servicio exclusivamente asistencial, a uno que realizaba una actividad docente-asistencial. Varias generaciones de becados de Medicina han pasado por este servicio transformado bajo la tutela de Ronald, y ahora son excelentes internistas. En esta época desarrolló una intensa actividad docente en Medicina y Nefrología, conectado con las Facultades de Medicina de las Universidades de Los Andes y Valparaíso.

Luego de muchos años de participación en su Directorio y Comités, Ronald fue elegido Presidente de la Sociedad Chilena de Nefrología en 2016, para servir en el cargo por un período de 2 años, lo que coincidió con la aparición de la grave enfermedad que le produjo la muerte. Fue una decisión valiente, que lo retrata enteramente, el ejercer el cargo a pesar del dolor y la extenuación que le producían su enfermedad y sus complejos tratamientos.

¿Quien fue Ronald más allá de su profesión, la medicina, a la que tanto amaba? Él era una persona de carácter fuerte, heredado de su padre, pero al mismo tiempo era tímido e introvertido en sus relaciones sociales. Era un hombre de familia; de su matrimonio con Pilar Bezamat tuvo dos hijos, Karen y Gabriel, a quienes amó entrañablemente y que le sobreviven. Los últimos 12 años de su vida los compartió con Sandra Horta, su fiel compañera, quien le contagió el amor por sus perros pastores alemanes, a quienes dedicaba gran parte de su tiempo libre. Ronald era un ser muy sensible, con conexiones profundas con el arte (herencia materna), y la ciencia (herencia paterna). Tenía un particular sentido de apreciación musical, siendo sus instrumentos preferidos el violín y el cello. Creía en la trascendencia y la divinidad, en que la vida tiene un sentido más allá de lo visible, sentido que él buscó incesantemente durante su vida.

Dr. Juan Carlos Flores Servicio de Nefrología y Diálisis Hospital Militar 